\title{
Erratum to: Absence of aquaporin-4 antibodies in patients with idiopathic intracranial hypertension
}

\author{
Samish Dhungana $\cdot$ Patrick Waters • Azza Ismail • \\ Nicola Woodroofe · Angela Vincent · Basil Sharrack
}

Published online: 14 April 2010

(C) Springer-Verlag 2010

\section{Erratum to: J Neurol \\ DOI 10.1007/s00415-010-5499-2}

The article was published under wrong category without abstract. The complete article is given here as Original Communication.

\begin{abstract}
The aetiology of idiopathic intracranial hypertension (IIH) is not clear. A dysfunction of the water channels could affect the cerebrospinal fluid (CSF) secretion or absorption and potentially contribute to its pathogenesis. We utilised a recently described anti-Aquaporin (AQP)-4 antibody assay to look for these antibodies in the serum and CSF of 10 symptomatic IIH patients and 10 control subjects. None of the patients or the controls had detectable anti-AQP-4 levels. Further investigation of other water channels, especially AQP-1, is being considered.
\end{abstract}

The online version of the original article can be found under doi:10.1007/s00415-010-5499-2.

S. Dhungana $\cdot$ A. Ismail $\cdot$ B. Sharrack

Department of Neurology,

Sheffield Teaching Hospitals NHS Trust,

University of Sheffield, Sheffield, UK

P. Waters $\cdot$ A. Vincent

Weatherall Institute of Molecular Medicine,

University of Oxford, Oxford, UK

N. Woodroofe

Biomedical Research Centre, Sheffield Hallam University,

Sheffield, UK

B. Sharrack $(\square)$

Department of Neurology, Royal Hallamshire Hospital,

Glossop Road, Sheffield S10 2JF, UK

e-mail: b.sharrack@sheffield.ac.uk

\section{Introduction}

The pathophysiology of abnormal cerebrospinal fluid (CSF) dynamics in idiopathic intracranial hypertension (IIH) is not clear [1]. In healthy individuals, CSF is mostly formed in the choroid plexus with small contributions from extrachoroidal tissues, including ependymal surfaces of the brain and the capillary-astrocyte complex in the bloodbrain barrier. It is reabsorbed into the dural venous sinuses through the arachnoid villi, although other sites are increasingly being recognised [10]. Several theories have been suggested to explain the aetiology of raised CSF pressure in IIH, including increased CSF production, impaired CSF absorption, obstruction of dural venous sinuses and increased brain volume due to cerebral oedema [6]. More recently, the potential role of proinflammatory CSF profiles have been suggested in some studies $[2,5]$.

Aquaporins are a recently discovered family of transmembrane water channels which play an important role in water homeostasis in the central nervous system (CNS) and are thought to be involved in the pathophysiologic mechanisms of cerebral oedema [3]. Aquaporin (AQP)-1 is natively expressed in the choroid plexus and contributes to water transport across the choroidal epithelium during CSF secretion. AQP-4 is more widely distributed within the CNS, including the choroid plexus [13] and ependymal cells of the ventricles [9]. Bloch et al. [4] suggested that AQP-4 could facilitate CSF absorption in hydrocephalus. Recently, antibodies to AQP-4 have been suggested to play a role in the pathogenesis of neuromyelitis optica (NMO) [11].

We hypothesised that a dysfunction of AQP-4 expression could affect CSF secretion or absorption and potentially contribute to the pathogenesis of IIH. In this study, we utilised a recently described anti-AQP-4 antibody assay [14] to look for AQP-4 antibodies in the serum and CSF of 
patients with IIH. We were not able to investigate the role of anti-AQP-1 antibodies because such an assay is currently not available.

\section{Methods and results}

Paired CSF and serum samples from 10 female symptomatic IIH patients [mean age $31.8 \pm 7.8$ years; mean body mass index (BMI) $33.4 \pm 6.9 \mathrm{~kg} / \mathrm{m}^{2}$ ] who were diagnosed according to the updated modified Dandy criteria [8] and 10 female control subjects (mean age: $35.8 \pm 12.1$ years; mean BMI: $\left.31.7 \pm 8.8 \mathrm{~kg} / \mathrm{m}^{2}\right)$ were examined for antiAQP-4 antibodies. Control subjects were patients who presented with headache and had lumbar puncture to exclude subarachnoid haemorrhage or raised intracranial pressure, and who were subsequently diagnosed with migraine or tension-type headache. The study was approved by South Yorkshire research ethics committee and all participants provided written informed consent.

Anti-AQP-4 antibody was measured by a quantitative fluorescence immunoprecipitation assay (FIPA) for each serum or CSF sample, as described elsewhere [14]. Samples were considered to be positive for the antibody when levels were above 63 fluorescence units (FU) (mean +3 SD value from 10 healthy control samples). Positive values in patients with NMO were between 100 and $600 \mathrm{FU}$ [14]. None of the IIH patients or controls had detectable antiAQP-4 antibodies in the serum or CSF (data not shown).

\section{Discussion}

Aquaporin-4 is a major antigen in NMO and its antibodies are detected in more than $75 \%$ of patients [14]. Unlike IIH, $\mathrm{NMO}$ is an immune mediated condition which is usually associated with severe inflammation of the spinal cord and the optic nerves and neutrophilic CSF pleocytosis [15]. Although the exact aetiology of IIH remains undetermined, the evidence of an inflammatory pathogenesis is controversial [7]. However a recent study suggested that brain lesions in some patients with NMO spectrum disorder may be accompanied by vasogenic oedema due to AQP-4 autoimmunity-related water flux impairment [12] and previous studies have shown increased water content of the brain tissue in patients with IIH [6]. If IIH is associated with AQP-4 autoimmunity, the differences between the clinical manifestations of this condition and NMO could be related to the differences in the IgG subclass distribution between these two diseases.

To our knowledge, this is the first study to investigate the role of AQP antibodies in IIH. Although our results suggest that anti-AQP-4 antibodies are unlikely to play a causative role in the pathogenesis of IIH, our sample size is very small and the possibility of anti-AQP-4 antibodies being responsible for a subset of patients with this condition cannot be excluded. Furthermore, the 63 FU cut-off value used in this study reflected the values noted in the control group in this experiment and was different from that used in our previous work (25 FU). Further investigation of water channels, especially the AQP-1 channel, in a large cohort of patients should be considered to fully understand the pathophysiology of raised intracranial pressure in this condition.

\section{References}

1. Ball AK, Clarke CE (2006) Idiopathic intracranial hypertension. Lancet Neurol 5:433-442

2. Ball AK, Sinclair AJ, Curnow SJ, Tomlinson JW, Burdon MA, Walker EA, Stewart PM, Nightingale PG, Clarke CE, Rauz S (2009) Elevated cerebrospinal fluid (CSF) leptin in idiopathic intracranial hypertension (IIH): evidence for hypothalamic leptin resistance? Clin Endocrinol 70:863-869

3. Bloch O, Manley GT (2007) The role of aquaporin-4 in cerebral water transport and edema. Neurosurg Focus 22:E3

4. Bloch O, Auguste KI, Manley GT, Verkman AS (2007) Accelerated progression of kaolin-induced hydrocephalus in aquaporin4-deficient mice. J Cereb Blood Flow Metab 26:1527-1537

5. Dhungana S, Sharrack B, Woodroofe NW (2009) Cytokines and chemokines in idiopathic intracranial hypertension. Headache 49:282-285

6. Dhungana S, Sharrack B, Woodroofe NW (2010) Idiopathic intracranial hypertension: a review. Acta Neurol Scand 121(2):71-82

7. Dhungana S, Sharrack B, Woodroofe NW (2009) IL-1beta, TNF and IP-10 in the cerebrospinal fluid and serum are not altered in patients with idiopathic intracranial hypertension compared to controls. Clin Endocrinol [Epub ahead of print]

8. Friedman DI, Jacobson DM (2002) Diagnostic criteria for idiopathic intracranial hypertension. Neurology 59:1492-1495

9. Graber DJ, Levy M, Kerr D, Wade WF (2008) Neuromyelitis optica pathogenesis and aquaporin 4. J Neuroinflammation 5:22

10. Johanson CE, Duncan JA III, Klinge PM, Brinker T, Stopa EG, Silverberg GD (2008) Multiplicity of cerebrospinal fluid functions: New challenges in health and disease. Cerebrospinal Fluid Res 5:10

11. Hinson SR, Pittock SJ, Lucchinetti CF, Roemer SF, Fryer JP, Kryzer TJ, Lennon VA (2007) Pathogenic potential of IgG binding to water channel extracellular domain in neuromyelitis optica. Neurology 69:2221-2231

12. Maganã SM, Matiello M, Pittock SJ, McKeon A, Lennon VA, Rabinstein AA, Shuster E, Kantarci OH, Lucchinetti CF, Weinshenker BG (2009) Posterior reversible encephalopathy syndrome in neuromyelitis optica spectrum disorders. Neurology 72:712-717

13. Speake T, Freeman LJ, Brown PD (2003) Expression of aquaporin 1 and aquaporin 4 water channels in rat choroid plexus. Biochim Biophys Acta 1609:80-86

14. Waters P, Jarius S, Littleton E et al (2008) Aquaporin-4 antibodies in neuromyelitis optica and longitudinally extensive transverse myelitis. Arch Neurol 65:913-919

15. Wingerchuk DM, Lennon VA, Pittock SJ, Lucchinetti CF, Weinshenker BG (2006) Revised diagnostic criteria for neuromyelitis optica. Neurology 66:1485-1489 